\title{
A emerxencia do neofalantismo como concepto sociolingüístico relevante: estado da arte na Galiza
}

\section{Maria Fernández Zas \\ Universidade da Coruña}

Data de recepción: 17/09/2019 | Data de aceptación: 02/12/2019

\begin{abstract}
Resumo:
Aínda que o número de galegofalantes continúa a diminuír de modo especialmente preocupante, nos últimos tempos o panorama sociolingüístico está a mudar de maneira significativa, presenciando o aparecemento dunha minoría urbana e falante nativa de español que reaxe con determinación perante o desequilibrio lingüístico na Galiza. Estas persoas neofalantes desempeñan un papel fundamental na transformación das ideoloxías e das prácticas lingüísticas, o que as torna unha peza chave no futuro da lingua galega. En concreto, neste artigo afondaremos no fenómeno do neofalantismo do punto de vista teórico, con énfase na recente proliferación de traballos académicos sobre esta cuestión tanto a nivel internacional canto nacional, en conformidade coa importancia que este fenómeno social posúe para a revitalización e a sobrevivencia das linguas minorizadas, incluíndo o idioma galego.
\end{abstract}

\section{Palabras chave:}

Lingua galega, neofalantismo, neofalante, sociolingüística, linguas minorizadas.

\section{Sumario:}

1. Introdución. 2. O neofalantismo na Galiza. 2.1. Definición. 2.2. Tipoloxía. 2.3. Perfil ideolóxico e modelos de lingua. 3. A emerxencia do neofalantismo como concepto sociolingüístico relevante. 3.1. Traballos sobre neofalantismo a nivel internacional e estatal. 3.2. Traballos sobre neofalantismo no espazo sociolingüístico galego. 4. Consideracións finais.

\section{The emergence of newspeakerness as a relevant sociolinguistic concept: state of the art in Galiza}

\footnotetext{
Abstract:

Whilst the number of speakers is now at alarming rates, the Galician sociolinguistic landscape has changed significantly in recent times, witnessing the emergence of an urban mi-
} 
nority of native Spanish speakers who react with determination to the linguistic imbalance in Galiza. These new speakers play a fundamental role in the transformation of language ideologies and practices, thereby becoming a key element in the future of the Galician language. Specifically, in this article we will analyse the phenomenon of newspeakerness from a theoretical point of view, with an emphasis on the recent proliferation of academic works on this issue both at an international and a national level, in accordance with the importance that this social phenomenon has for the revitalisation of minoritised languages, including the Galician language.

\section{Key words:}

Galician language, newspeakerness, new speaker, sociolinguistics, minoritised languages.

\section{Contents:}

1. Introduction. 2. Newspeakerness in Galiza. 2.1. Definition. 2.2. Typology. 2.3. Ideological profiles and language models. 3. The emergence of newspeakerness as a relevant sociolinguistic concept. 3.1. Works on newspeakerness at an international and national level. 3.2. Works on newspeakerness in the Galician sociolinguistic space. 4. Final reflexions. 


\section{Introdución}

Hoxe en día, case 40 anos após o inicio do período autonómico e a subsecuente aprobación da Lei de normalización lingüística, os inquéritos e os estudos sociolingüísticos (p. ex. IGE, 2011 e MSG, 2007 e 2008) mostran claramente que o galego está a vivir a peor situación da súa historia en termos cuantitativos. Paradoxalmente, desde o comezo da década de 1980, esta tendencia crecente cara ao abandono do galego decorre en simultáneo co aumento do apoio institucional e coa presenza da lingua no sistema de ensino, nos medios de comunicación e nos organismos públicos. Ao paso que as medidas adoptadas pola Xunta da Galiza conseguiron mellorar algo as actitudes lingüísticas da populación a respecto do galego (González González, 2003; MSG, 2011; Observatorio da Lingua Galega, 2011 e 2017), ben como o status da que outrora era unha lingua profundamente desprestixiada, os preconceptos lingüísticos están aínda presentes demais na mentalidade da sociedade galega (Iglesias Álvarez, 2002; Freixeiro Mato, 2009).

Neste sentido, a política lingüística levada a cabo na Galiza, que ben poderiamos definir como unha política reactiva e de baixa intensidade (Lorenzo Suárez, 2005), non tivo en consideración o feito de que a aparente vitalidade do galego en termos cuantitativos ocultaba tendencias moito máis negativas, cal é o baixo uso deste idioma entre a populación urbana en xeral e, particularmente, entre as faixas etarias máis novas. Porén, desde as últimas décadas do século pasado o panorama sociolingüístico galego está a mudar paseniñamente, asistindo á emerxencia dunha minoría urbana que manifesta a súa insatisfacción no relativo ao desequilibrio lingüístico na Galiza e que desafía o actual statu quo a través do seu compromiso co uso activo da lingua galega (Ramallo, 2013; O’Rourke \& Ramallo, 2015; O'Rourke, 2018). En moitos casos, para estes novos e novas utentes educadas en español o simple feito de falaren galego constitúe unha forma de resistencia perante a ausencia dunha clara vontade política de forma a efectuar unha verdadeira mudanza sociolingüística na Galiza, chegando mesmo ao punto de deslocaren completamente a súa primeira lingua co fin de adoptaren prácticas monolingües en galego.

$\mathrm{Na}$ actualidade, máis do que nunca, fica claro o papel fundamental destes novos e novas falantes na perspectiva de analizarmos o porvir do idioma galego e, por conseguinte, é fundamental coñecermos a natureza e o pensamento lingüístico deste colectivo. Só así se poderán deseñar e desenvolver políticas precisas e debidamente orientadas que contribúan tanto para a atracción de novos e novas utentes como para a manutención dos e das actuais. Con efecto, é a grande importancia deste grupo de persoas neofalantes, xa posta en relevo en González González (2003: 189), a que explica a proliferación de traballos publicados nos últimos anos sobre o tema. 


\section{O neofalantismo na Galiza}

\subsection{Definición}

Como acabou de ser salientado, o neofalantismo constitúe un tema de actualidade no ámbito sociolingüístico nacional e internacional. Porén, a pesar da grande cantidade de traballos neste dominio, "non hai consenso con respecto ao que se entende por neofalante e termos afíns" (O'Rourke \& Ramallo, 2013a: 90). En xeral, a parafrasearmos O'Rourke \& Pujolar (2013: 56), as nocións de neofalantismo e de neofalante describen as formas de falar e as prácticas sociais e lingüísticas dos e das falantes que existen fóra das comunidades tradicionais de falantes nativas e nativos, abranxendo contextos tan diversos como a inmigración, a colonización e a globalización, entre outros. Para O'Rourke \& Walsh (2015: 64), as persoas neofalantes son aqueles individuos que adquiriron a súa lingua nun contexto diferente do doméstico, isto é, a través de programas de inmersión ou educación bilingüe. Indubitabelmente, esta definición é moito lata, pois inclúe un amplo leque de tipoloxías de falantes e de graos de competencia lingüística. Por seu turno, O’Rourke \& Ramallo (2013a: 90) definen o individuo neofalante como unha persoa que se torna "usuaria habitual, con frecuencia exclusiva, dunha lingua que non foi a súa lingua materna ou familiar". Na maioría dos casos, este idioma foi aprendido na socialización secundaria, nomeadamente a través do sistema de ensino. No que di respecto ao galego, a seguirmos O'Rourke \& Ramallo (2013b: 288-289), o termo neofalante é usado como un concepto popular e académico para retratar os e as falantes que son criadas falando español, mais que nalgún momento das súas vidas, xeralmente na adolescencia ou no inicio da idade adulta, se converten en utilizadores do galego, moitas veces debido a factores político-ideolóxicos e/ou socioculturais.

Este colectivo é, en grande parte, o produto das políticas lingüísticas que comezan a vigorar na década de 80, após a transición española, por causa da inclusión do galego en ámbitos e espazos onde non estaba presente, como os medios de comunicación e a administración pública, por exemplo. Deste modo, no caso específico da Galiza, o fenómeno do neofalantismo presenta características distintivas notorias, unha vez que actualmente a maioría da populación galega é bilingüe e posúe un elevado nivel de proficiencia en español e en galego, quer de maneira activa, quer de xeito pasivo. Por esta razón, ao contrario do que acontece noutras comunidades europeas, tanto a exposición precoz ao galego como a alta competencia lingüística das persoas que moran na Galiza non son necesariamente resultado da escolarización formal, mais, como salientan Ramallo \& O’Rourke (2014: 99), a aprendizaxe do idioma tamén pode ser ambiental. Téndomos debidamente en conta a situación de conflito lingüístico que existe no país, cómpre notarmos que nas persoas neofalantes de 
galego se verifica unha condición pouco usual, a saber: o deslocamento da lingua "normal" e de poder en beneficio dunha outra estigmatizada e con moito menos prestixio social. Nesta perspectiva, pódese dicir que o neofalantismo constitúe un movemento social "conformado por suxeitos que adoptan unha práctica consciente de defensa e activismo a prol das linguas socialmente minoritarias, mediante o seu uso, a súa reivindicación pública e a súa dignificación social" (Ramallo, 2013: 254255). Por conseguinte, as persoas neofalantes conforman unha "minoría activa" (Moscovici \& Mugni, 1983), innovadora e moito motivada que rexeita o statu quo lingüístico e que tenta transformar a sociedade desde abaixo co fin de mudar as estruturas de poder existentes. Así, o neofalantismo é "con certeza unha forma de rebelión, xa que entraña dificultades, afouteza [e] un esforzo sostido durante un período de tempo moito alongado (até que aparece o hábito). É tanta a enerxía necesaria a investir que non se pode considerar un simple capricho" (Dans, 2017: 54).

\subsection{Tipoloxía}

Embora non sexa un grupo homoxéneo, mais si diverso e complexo, as persoas neofalantes costuman compartillar unha serie de características sociolingüísticas, sociodemográficas e socioculturais que, consoante O'Rourke \& Ramallo (2018: 94), corresponden a un perfil de falante novo ou nova e de clase media urbana, desde unha perspectiva socioeconómica. No entanto, convén salientarmos o feito de tamén se rexistraren neofalantes en ambientes rurais e periurbanos e pertencentes a distintas clases sociais. En termos numéricos, aínda que non hai informacións exactas, pois non existen até agora estudos cuantitativos dirixidos a estas persoas, o antecitado colectivo representa apenas unha pequena parte da populación total galega, sobre todo en comparación cos números correspondentes na Cataluña e en Euskadi. A tomarmos como punto de referencia os inquéritos do Instituto Galego de Estatística (IGE, 2011), os datos indican que, no ano 2008, 70.000 persoas españolfalantes, que constitúen aproximadamente $2 \%$ da populación, “desprazaron o castelán para convertérense en falantes activos de galego" (Ramallo, 2013: 251). Do punto de vista xeográfico, segundo afirman Monteagudo, Loredo, \& Vázquez (2016: 27), Santiago de Compostela é a cidade que ten "o maior tanto por cento de neofalantes, a máis baixa porcentaxe de desgaleguizados e un amplo grupo de galegofalantes de orixe galega".

Relativamente aos perfís destes novos e novas falantes, Ramallo \& O'Rourke (2014) presentan unha proposta de clasificación pouco restritiva que ten en conta utentes cuxa lingua habitual non é o galego. Así, estes autores consideran distintos perfís de neofalantes con base no seu uso do idioma, dividíndoos en catro grupos. En primeiro 
lugar, as persoas "neofalantes esenciais" son aquelas que pasan a falar galego de modo exclusivo ou, cando menos, con moita frecuencia. Os e as "neofalantes funcionais", por súa vez, son as que empregan o galego "en interacciones informales o en contextos institucionales en los que este es el idioma predominante". Por outro lado, as persoas "neofalantes ocasionais" son aqueles individuos que fan "un uso limitado del gallego aprendido, generalmente como una práctica reactiva a los estímulos de la interacción. Finalmente, as e os "neofalantes potenciais" son todas aquelas persoas que, a pesar de teren o español como lingua habitual, son "bilingües receptivos con una autopercepción de su capacidad para hablar gallego muy elevada" (Ramallo \& O’Rourke, 2014: 100). Conforme sinalan Tomé \& Evans (2018: 107), unha clasificación deste teor "desatende outros aspectos esenciais para a definición convencional de neofalantes galegos", como o deslocamento "da lingua maioritaria e as causas que motivan o uso desta lingua". Infelizmente, a parafrasearmos Ramallo (2012: 183-184), aínda non existe ningunha tipoloxía que aborde de maneira global cuestións tan relevantes como a motivación para a mudanza lingüística, o ambiente social de referencia, a construción da identidade e o modelo de lingua aprendido, ben como o dominio formal da lingua e a propia experiencia lingüística.

\subsection{Perfil ideolóxico e modelos de lingua}

Noutra orde de ideas, o deslocamento da lingua dominante, neste caso o español, entre os novos e as novas usuarias do galego costuma dar orixe á construción de novas identidades en resposta ou en oposición a outros perfís de falantes, pois, como é sabido, as linguas teñen adoito unha forte compoñente identitaria. Deste modo, de acordo con O'Rourke \& Ramallo (2018: 95), as persoas neofalantes constrúen e negocian a súa identidade en diferenza con varios "outros", incluíndo unha xeración máis vella de falantes tradicionais de galego, as galegas e os galegos españolfalantes e até mesmo outros suxeitos neofalantes. $\mathrm{Na}$ verdade, a relación entre lingua e identidade é unha cuestión que suscita moitos puntos de vista diferentes e, ás veces, diverxentes. Porén, é innegábel que para moitas persoas a lingua desempeña un papel esencial na definición da súa identidade de grupo, o que a converte nun recurso precioso e merecedor de protección.

Así as cousas, o alicerce deste vínculo foi normalmente organizado en volta do falante nativo, ao cal se asocian "adxectivos como «auténtico», «puro» e «innato»" (O’Rourke \& Ramallo, 2011: 1685). Neste sentido, as e os falantes tradicionais son adoito considerados como os únicos falantes auténticos e lexítimos e, por tanto, son eles os gardiáns da "verdadeira" identidade lingüística, non tendo en conta deste modo a emerxencia de novas clases de falantes que traen consigo outros valores 
lingüísticos e culturais, ás veces moito diferentes dos da comunidade de falantes tradicionais. A este respecto, Tomé \& Evans (2018: 102) destacan que o termo neofalante "non fai referencia á competencia lingüística dos falantes (nin na lingua maioritaria nin na minoritaria), senón exclusivamente á súa experiencia lingüística". Na mesma liña, Frías Conde (2006: 60) apunta que "a diferenza entre estes dous tipos de falantes é basicamente unha: o neofalante aprendeu a lingua, mentres que o paleofalante [falante tradicional] a adquiriu". No entanto, independentemente do feito de isto ser verdade, cando menos na teoría, na realidade "o termo 'falante nativo' utilízase con frecuencia como un arquetipo restritivo para xustificar xerarquías de falantes" (Ramallo, 2013: 248). Consecuentemente, non restan dúbidas de que a aparición destas persoas neofalantes na escena sociolingüística "abre também um conflito quanto à questão de quem são os e as falantes legítimas e autorizadas da língua galega" (Padín, 2017: 8).

Con efecto, a figura do suxeito neofalante ten sido observada con desconfianza, a padecer na propia pel unha profunda incomprensión por parte dos e das falantes tradicionais, ben como das persoas españolfalantes. Nos espazos urbanos, as oportunidades que teñen estes individuos para se exprimiren en galego son moito limitadas, até ao punto de o simple feito de unha persoa falar esta lingua ser visto nalgúns contextos como unha violación das normas sociais estabelecidas e unha ameaza para a supremacía do idioma dominante. Na Galiza, o español da mocidade continúa a ser a lingua neutra e "normal" nos procesos de socialización. En contrapartida, o galego dos mozos e das mozas neofalantes costuma vir asociado a unha moda e, máis frecuentemente, a unha orientación política nacionalista máis ou menos radical, cando, na verdade, non son poucos os casos de novos e novas utentes do galego que revelan ter outras razóns para o deslocamento parcial ou total do español. Obviamente, estas connotacións teñen efectos negativos e prexudiciais para o idioma, xa que "se axir como elemento marcado ou connotado na comunicación, terá máis difícil ser unha lingua con perspectivas de futuro" (Freixeiro Mato, 2009: 140).

Para alén de conviviren coa incomprensión e co preconcepto de seren xulgadas probabelmente como nacionalistas, de acordo con O'Rourke \& Ramallo (2011: 1685), as persoas neofalantes tamén son avaliadas en función da súa variedade lingüística, que tende a ser descrita como "«artificial», «contaminada» e «adquirida»", nomeadamente por parte das xeracións máis novas de falantes tradicionais, que ven estes suxeitos como uns usurpadores que tencionan ocupar un espazo social que non lles pertence. Con todo, esta representación das variedades usadas polos neofalantes non está presente no imaxinario dos e das falantes tradicionais máis idosas, que consideran que este colectivo "se expresa nun galego máis «coidado», máis «puro», máis «correcto», máis «auténtico» e máis «exemplar»" (Ramallo, 2010: 34). 
No relativo á lingua deste novo usuariado, hai actualmente diverxencia de pareceres. Así, en canto para algúns autores se trata dun "modelo estable e valorado ben valorado socialmente" (Regueira, 1999: 869), outros acreditan que o galego urbano é un perigo, pois está "xerando un complexo de minusvaloración da variedade auténtica propia de moitos galegofalantes, que ven como a súa variante lingüística segue sen ter valor social" (González González, 2008: 48). Co fin de ilustrar este fenómeno, Monteagudo (2017: 38) fai un breve percurso polos trazos máis distintivos do chamado "neogalego urbano", a se centrar no uso oral da lingua, incluíndo na súa análise a prosodia, a fonética, a morfosintaxe, os idiomatismos e a pragmática:

entoación castelá, indistinción do timbre das vogais medias, pronuncia alveolar do [y] velar, indiferenciación do /s/ (apical) e o / $\mathrm{g} /$ prepalatal, non realización de contraccións, elisións vocálicas e outros fenómenos fonotácticos propios do galego, emprego de tempos verbais compostos [...], indistinción de te (acusativo) e che (dativo), [...] realización de usos pronominais do castelán inexistentes en galego, [...] confusión das regras sintácticas de énclise e próclise.

No entanto, a este respecto convén non facermos xeneralizacións abranxentes, pois, consoante Ramallo (2013: 250), as neofalas constitúen "un continuo que percorre desde formas de expresión altamente ligadas ao estándar, cun uso formal moi esmerado, a aqueloutras moi interferidas pola lingua materna e de primeira socialización dos novos usuarios". Non é de estrañar, por tanto, que na realidade algunhas persoas neofalantes se expresen "moito mellor, cun grao de pureza da lingua superior, que os paleofalantes". Isto débese ao feito de o suxeito neofalante "aprender un modelo de lingua depurado", ao paso que "o paleofalante, na grande maioría dos casos, exprésase cunha linguaxe mixta” (Frías Conde, 2006: 61). Por esta razón, a pesar de moitas destas persoas non adquiriren espontaneamente a lingua pola vía da socialización primaria, é posíbel que, após varios anos de práctica e de exposición ambiental, familiar e/ou social ao galego, poidan atinxir unhas competencias lingüísticas moito próximas ou mesmo semellantes ás que posúen os e as falantes nativas.

Sexa como for, o que é claro é que as novas e os novos falantes demandan recoñecemento como grupo social e lingüístico, embora, consoante O'Rourke \& Ramallo (2018: 104), ás veces mostren un sentimento de inseguranza ao exixiren tales reivindicacións, desvalorizando deste modo a súa propia capacidade lingüística e negándose a si propios o dereito de existiren como falantes reais ou lexítimos. Porén, paradoxalmente, a maioría destes individuos é consciente de que o modelo lingüístico tradicional que visa alcanzar no futuro está a desaparecer e que, por conseguinte, o seu uso activo e consciente do galego é fundamental para garantir a súa sobrevivencia. 


\section{A emerxencia do neofalantismo como concepto sociolingüístico relevante}

Debido ás especificidades culturais, económicas, sociais e políticas do noso país, no galego rexístrase un desfasamento cronolóxico significativo no que di respecto á publicación de contributos consagrados ao estudo das particularidades da nosa lingua e das persoas que a falan, contrariamente ao que aconteceu cos idiomas do seu contorno, que principiaron o seu percurso filolóxico no inicio da Idade Moderna. Como vira obvio, este desfasamento secular afectou tamén o desenvolvemento de traballos sociolingüísticos centrados na análise e subsecuente inversión das tendencias negativas en materia de lingua, pois os autores e as autoras galegas desatenderon esta área de investigación durante décadas. Felizmente, a antecitada demora xa está parcialmente resolvida grazas á saída do prelo nos últimos anos de traballos moito rigorosos que visan ofrecer novas visións a respecto das linguas minorizadas e das minorías lingüísticas, ao paso que fornecen unha revisión e subsecuente actualización de conceptos chave como "paleofalante" ou "falante tradicional" (native speaker), "neofalante" (new speaker) e "neofalantismo" (newspeakerness).

\subsection{Traballos sobre neofalantismo a nivel internacional e estatal}

Como ben salientan Marten, van Mensel, \& Gorter (2012: 1), a investigación tradicional sobre as linguas minorizadas centrouse na manutención da lingua e na mudanza lingüística en proveito da lingua dominante, no perigo de extinción e na revitalización do idioma, na transmisión familiar, na educación e nas políticas lingüísticas noutros dominios sociais, como os medios de comunicación. Neste sentido, consoante O'Rourke (2011: 3), desde a segunda metade do século XX até hai ben poucas décadas, os contributos consagrados á análise destas linguas dirixiron o ollar a eventos macrosociais como causas directas da súa sobrevivencia ou declinio. Igualmente, é interesante notarmos que durante este primeiro período os antecitados estudos se concentran apenas naqueles contextos en que os e as falantes abandonan a lingua minoritaria e/ou minorizada para abrazaren o idioma dominante, sen ponderaren a posibilidade inversa, isto é, aqueles casos en que unha ou varias persoas deciden deslocar a lingua de poder da comunidade a favor dunha outra variedade estigmatizada.

No que di respecto á análise do proceso de substitución lingüística en distintos espazos lingüísticos minorizados, é digno de nota o traballo de Uriel Weinreich (1979), primeiro autor en empregar o termo language shift para se referir á mudanza 
do uso dunha lingua habitual por outra diferente. Sobre este asunto, sobrancea outrosí o traballo de Fishman (1991), que no libro intitulado Reversing Language Shift $(R L S)$ combina nocións sociolóxicas teóricas sobre a mudanza de linguas (language shift) e o planexamento lingüístico (language planning) con estudos de caso e comentarios prácticos sobre os esforzos destinados á preservación das linguas ameazadas (endangered languages). Así, ao contrario do que expoñen Dorian (1980), Ninyoles (2005) e Freixeiro Mato (2010), que enumeran tres factores chave en relación coa consumación do proceso de substitución lingüística, como son o número de falantes, os espazos de uso e a erosión interna da lingua, Fishman coloca o foco na importancia da transmisión interxeracional no momento de avaliar a saúde de calquera lingua en perigo, secundarizando deste modo os restantes elementos antecitados. Nesta liña de pensamento, mais decorridos dez anos da saída do prelo de $R L S$, Fishman (2001) edita unha outra obra que ten como título Can threatened languages be saved?, onde, a través dun conxunto de artigos de diversa autoría, se analiza a posición contemporánea de 18 linguas ameazadas espalladas polos cinco continentes, algunhas das cales xa foran consideradas na obra anterior, como o éuscaro e o catalán ${ }^{1}$. Desa forma, o sociolingüista estadounidense pon a proba a validez das súas propias teorías, ao paso que fornece informacións sobre o que está a acontecer coas linguas minoritarias e minorizadas que loitan cada día pola súa recuperación e sobrevivencia. Indubitabelmente, para este autor, e tamén para outros estudiosos, "os factores que conducen á morte das linguas non escapan ao control humano" (Crystal, 2003: 65), xa que sempre existe unha maneira de mellorar a situación destes idiomas, embora en maior ou menor grao. Igualmente dignos de nota son os artigos recompilados no volume The Cambridge Handbook of Language Policy (Spolsky, 2012), onde desde unha óptica algo diferente, o profesor neozelandés aborda a política lingüística de maneira integrada, a abranxer cuestións tan variadas como as prácticas e o activismo lingüístico, os métodos e as institucións consagradas á xestión das linguas, as crenzas e os preconceptos asociados ás distintas variedades, ben como as causas subxacentes aos procesos de substitución lingüística.

Por súa vez, os contributos recentes sobre as linguas minorizadas e as minorías lingüísticas caracterízanse polo estudo das linguas nas súas dimensións microsocial e individual. Neste sentido, O’Rourke (2011: 3) destaca que é só a través da análise

1 Aínda que Fishman non fornece informacións sobre o galego neste traballo, cómpre salientarmos as súas palabras no 'postscript' á tradución galega dun contributo seu, onde afirma que el foi probabelmente "the only person who has written about Galicia, Gallego and the Gallegos in Yiddish $[\ldots]$ as an expression of the admiration that only a concerned native speaker of one small and abused language can have for another that is in roughly similar circumstances", ao paso que manifesta o desexo de que a antecitada tradución sexa útil "not only to understand but also to ameliorate the manifold problems that lie before the ancient and honorable Galician tongue" (Fishman, 1997: 51-53). 
das crenzas, das actitudes e das ideoloxías lingüísticas dos e das falantes que estes procesos poden ser debidamente avaliados. Para alén diso, conforme mencionado anteriormente, as estudiosas e os estudiosos comezan a concentrar a súa atención nas mudanzas lingüísticas que pretenden coadxuvar en reverter a situación inxusta das linguas minorizadas. Como é evidente, esta grande viraxe veu acompañada por unha diversificación tanto das liñas e métodos de investigación canto dos suxeitos de estudo. Á luz da crecente atención conferida ao fenómeno global do neofalantismo recentemente, son moitos os contributos que visan revisitar e reavaliar aspectos tan fundamentais como a distinción entre "falante nativo" e "neofalante" (O'Rourke \& Pujolar, 2013; Jaffe, 2015; Atkinson, 2018; Murchadha, Hornsby, SmithChristmas \& Moriarty, 2018) ou o papel chave das "minorías lingüísticas" (May, 2008; Moscovici \& Mugny, 1983). Na verdade, a cuestión do "falante nativo" como sinónimo de "falante-ouvinte ideal", cando menos nunha perspectiva teórica, xa captou o interese de Chomsky (1971: 5) e mesmo de Fishman (1991), para quen a recuperación de calquera lingua está intimamente ligada á reconstrución da comunidade de falantes nativas e nativos.

No entanto, non foi até á saída do prelo do libro intitulado The Native Speaker Is Dead! (Paikeday, 1985) que esta dicotomía se converteu nunha cuestión de preocupación na lingüística aplicada, unha vez que o uso dos antecitados rótulos, para alén de ser lingüisticamente reducionista, "[can] become discriminatory in some of its applications, especially since it happens to favour one group of speakers of each language against all others" (Paikeday, 1985: 30). Con efecto, este contributo abriu camiño a posteriores debates, case todos eles concordantes coas conclusións de Paikeday, como é o caso de Davies (2003) e de Piller (2001 e 2002), os cales consideran que as cualidades únicas e singulares atribuídas ás persoas nativas nunha lingua son máis un mito e unha idealización do que unha realidade, xa que a oposición fundamental entre os conceptos "falante nativo" e "neofalante" non é o nivel de autenticidade e de competencia lingüística, que mesmo poden vir a ser semellantes co pasar do tempo, mais a motivación e a vontade do novo falante de asumir confianza e identidade. Na verdade, como argumentan O'Rourke \& Pujolar (2013: 61), a emerxencia de novos falantes de linguas minorizadas comezou a desafiar a crenza de que unha comunidade de falantes nativos é necesaria para un idioma sobrevivir, tal como defendía Fishman (1991: 92-95). Esta nova visión do papel das persoas neofalantes no proceso de revitalización das linguas en perigo está ligada á crecente influencia destas minorías activas na chamada "nova orde sociolingüística" (O’Rourke, Pujolar, \& Ramallo, 2015). O que todas estas minorías partillan, consoante Moscovici \& Mugny (1983: 42), "is the tendency to seek visibility, to forge an identity, to convert the majority to their ideas and beliefs, in short, to change the groups or societies to which they belong. In other words, 
they are factors of innovation". Estas palabras teñen todo o sentido se aplicadas ao galego, visto que, como Dorian (1981: 39) observa moito acertadamente cando trata a situación conflitiva do escocés, "who speaks the language is ultimately more important than how many speak it" (énfase no orixinal).

Após esta breve análise, e antes de aprofundarmos no caso da Galiza, convén considerarmos como se manifesta o fenómeno do neofalantismo noutros territorios en que conviven dúas ou máis linguas nunha situación de desigualdade. Na Europa, esta liña de investigación está certamente moito explorada, nomeadamente con base na utilización de técnicas cualitativas, a seren abondosos os contributos centrados nas especificidades das persoas neofalantes do irlandés (O'Rourke, 2011; O’Rourke \& Ramallo, 2011; O'Rourke \& Walsh, 2015), do corso (Jaffe, 2015), do bretón (Ferguson, 2006; Hornsby, 2016), do escocés (McLeod \& O'Rourke, 2015; McLeod, O’Rourke, \& Dunmore, 2014), do galés (Ferguson, 2006; Selleck, 2018), do hebraico (Hornsby, 2015), do lombardo (Coluzzi, 2018) e do occitano (Costa, 2015), entre outros. Por súa vez, no espazo ibérico, a situación é semellante á verificada nos países europeos, tornando posíbel acharmos traballos que analizan a biografía lingüística, as actitudes, as motivacións e as competencias lingüísticas das persoas neofalantes de éuscaro (Urla, 2012; Ortega, Amorrortu, Goirigolzarri, Urla, \& Uranga, 2014; Puigdevall, Walsh, Amorrortu, \& Ortega, 2018; Lantto, 2018) e catalán (Pujolar, González, \& Martínez, 2010; Pujolar \& Puigdevall, 2015; Puigdevall, Walsh, Amorrortu, \& Ortega, 2018).

\subsection{Traballos sobre neofalantismo no espazo sociolingüístico galego}

Pasándomos agora ao tratamento desta materia na Galiza, convén comezarmos este percurso dando especial relevancia ao grande desenvolvemento experimentado neste dominio durante a última década. Hoxe en día, isto reflíctese na larga variedade de focaxes e de áreas de investigación abertas, ben como no crecente número de autores e autoras que están a desempeñar un papel impulsionador nos estudos sobre o fenómeno do neofalantismo no espazo sociolingüístico galego. Como xa se comentou, aínda non se tirou do prelo unha obra completa que aborde esta temática, mais son moitos os artigos académicos e as teses de mestrado e de doutoramento que poñen o foco neste tema.

Así, do punto de vista teórico, deben salientarse os contributos de Ramallo, que é indubitabelmente o autor galego que máis está a contribuír para unha comprensión abranxente e integrada deste fenómeno. Máis concretamente, cómpre 
facermos referencia aos artigos que teñen por título "Neofalantismo" (2013) e "O neofalantismo e o suxeito neofalante" (2018), en que o autor aprofunda na orixe contemporánea deste colectivo e na súa presenza na Galiza actual, ao paso que presenta unha proposta teórica deste fenómeno, entendido como "un acontecemento político emancipador" (Ramallo, 2018: 737). Debe ser citado, outrosí, máis un outro traballo do antecitado investigador que, so o título de "Cara a unha tipoloxía sociolingüística dos falantes de galego" (2010), visa proporcionar unha clasificación básica dos tipos de utentes deste idioma na Galiza actual. Deste modo, ao carón dos e das galegofalantes tradicionais, profesionais, ocasionais, ocultos en público e bilingües, Ramallo inclúe os neofalantes, isto é, "as persoas que non tiveron o galego como lingua familiar e que utilizan esta lingua habitualmente" (2010: 33).

Por seu turno, en coautoría con O'Rourke, temos de facer referencia aos artigos "Neofalantes as an active minority: Understanding language practices and motivations for change amongst new speakers of Galician" (O'Rourke \& Ramallo, 2015), onde os autores e as autoras tentan explicar as prácticas lingüísticas e as motivacións que se ocultan detrás da mudanza lingüística destes novos e novas falantes do galego, e "Identities and New Speakers of Minority Languages: A Focus on Galician” (O’Rourke \& Ramallo, 2018), que examina os comportamentos lingüísticos e os trazos identitarios que caracterizan este colectivo. Igualmente notábel é a aproximación que fan os antecitados autores aos perfís xerais das persoas galegofalantes no artigo redixido en español e intitulado "Perfiles de neohablantes de gallego" (Ramallo \& O'Rourke, 2014), en que estes pesquisadores consideran distintos perfís de neofalantes a teren en conta o seu uso real do idioma (véxase 2.2). Con certeza, esta clasificación ten grande relevancia, pois vai alén da dicotomía entre neofalantes e paleofalantes a que fai referencia Frías Conde (2006) nun seu traballo en que trata sobre esa primeira categoría de falantes na Romania. Por outro lado, tamén son varios os traballos consagrados á comparación de dous contextos lingüísticos minorizados como son o galego e o irlandés. Así, por colocarmos un exemplo, "Los nuevos hablantes de lenguas minoritarias: una comparación entre Irlanda y Galicia" (O’Rourke \& Ramallo, 2011) examina as tensións que xorden entre as locutores e os locutores nativos e non nativos en ambos os contextos, tendo en conta os factores históricos, sociopolíticos e socioeconómicos que conduciron ao aparecemento desa categoría de falantes.

Noutra orde de ideas, a propia O'Rourke tamén introduce brevemente a cuestión do neofalantismo no texto intitulado "The Galician Language in the TwentyFirst Century" (O'Rourke, 2014), para publicar varios anos despois "Just use it! Linguistic conversion and identities of resistance amongst Galician new speakers" (O’Rourke, 2018), un artigo que explora as ideoloxías subxacentes ao deslocamento da lingua dominante, ben como o papel que desempeñan as persoas neofalantes 
como planificadoras da lingua na Galiza contemporánea. Para alén diso, é pertinente mencionarmos o traballo de investigación de Kováčová-Moman (2007), intitulado A mudança da língua usual nos novos locutores de galego - neofalantes, no cal, a través de 20 entrevistas e un estudo de caso, a autora examina as causas que conduciron ao abandono parcial ou total da lingua maioritaria, ao paso que se interesa na transmisión interxeracional da lingua neste mesmo grupo. Máis un contributo interesante nesta liña, aínda que desde unha perspectiva menos académica, son as Historias de neofalantes de Dans (2017: 8) que, como o propio título da monografía indica, "se mergullan nas motivacións, pareceres, problemas, alegrías e penas [...] de trinta e oito persoas de ambos os sexos e de idades díspares", reflectindo ao mesmo tempo sobre cuestións tan fundamentais como a adhesión de novos e novas falantes provenientes do español, ben como o papel reservado a este colectivo no proceso de revitalización do galego.

Un caso especial constitúeo o artigo que ten por título "Neofalantes e travestismo lingüístico: un experimento sociolóxico e didáctico sobre ideoloxías, obstáculos e persistencia", que se aproxima do neofalantismo desde o ámbito da Educación a través dun experimento de inmersión lingüística dirixido principalmente aos perfís de neofalante potencial e neofalante funcional. Como indica a autora (Mosquera Castro, 2018: 655), esta é "unha perspectiva pouco explorada mais de notábel relevancia", así como o é tamén a abordaxe de Padín (2017) no seu traballo de fin de mestrado intitulado Neofalantes na Era Digital. Neste último caso, trátase, sen dúbida, dunha focaxe pioneira que, nas palabras do propio autor (2017: 4), visa descubrir "se as Tecnologias da Informação e Comunicação (TIC) oferecem às pessoas neofalantes de galego um cenário propício para se apresentarem como falantes dessa língua e para experimentarem linguística e identitariamente como falantes de galego".

O neofalantismo, ou mellor dito, a lingua destas persoas neofalantes tamén é obxecto de estudo nos traballos consagrados á análise da variación sociolingüística da Galiza. Neste sentido, seguindo a clasificación dos sociolectos galegos que fornece Dubert (2002: 16-19), Monteagudo (2005: 421) inclúe nas variedades faladas no país o "para-galego" ou "neo-galego urbano", que, a seu ver, é

un interlecto mixto producido por falantes iniciais do castelán exemplar ou rexional, cun nivel elevado de instrución, que conseguiron unha aprendizaxe defectuosa do galego; a categorización desta variedade é disputada: galego (incluso exemplar) para os seus locutores e para un sector da comunidade lingüística, castelán superficialmente galeguizado para outro sector da mesma.

Nesta perspectiva, o cuestionábel relacionamento entre "neo-galego urbano" e "aprendizaxe defectuosa", moito recorrente en determinados sectores da popula- 
ción galega, é o tema central do artigo que ten por título “A miña variedade é defectuosa': a lexitimación social das neofalas" (O’Rourke \& Ramallo, 2013a). Así, a través dos discursos producidos en tres grupos de discusión con falantes tradicionais e neofantes, os autores observan as tensións existentes entre ambos os colectivos "sobre cales das formas da lingua son consideradas correctas, sobre que falantes son lexítimos usuarios do idioma e sobre quen ten acceso e control respecto dos recursos lingüísticos nos emerxentes mercados lingüísticos" (O'Rourke \& Ramallo, 2013a: 100). Con efecto, esta é unha polémica de longa data que, como é sabido, xa fora abordada, cando menos en parte, nos primordios deste século nas monografías intituladas Os falantes como lingüistas (Kabatek, 2000) e Falar galego: "no veo por qué" (Iglesias Álvarez, 2002), ben como no recente artigo que ten por título "Competing ideologies of linguistic authority amongst newspeakers in contemporary Galicia” (O'Rourke \& Ramallo, 2013b). A este respecto, para Regueira (1999: 869), "existen indicios suficientes para defende-la idea de que se trata [o neo-galego urbano] dun modelo estable e ben valorado socialmente". No entanto, concordamos coas palabras de O'Rourke \& Ramallo (2013a: 89) cando afirman que "o espazo sociolingüístico das neofalas e dos neofalantes precisa de máis recoñecemento social”.

Desde unha perspectiva máis claramente lingüística, deben ser citados os traballos intitulados "O novo galego urbano" (González González, 2008), "Estándar oral e variación social da lingua galega" (Regueira, 1999) e "Lingua e Sociedade en Galicia" (Monteagudo, 2017), que, a mostraren apenas algunhas diferenzas entre eles, presentan os principais trazos lingüísticos do chamado neogalego urbano. Este tipo de galego, en xeral altamente interferido polo español, posúe "unha serie de características que afectan tanto ao plano fonético coma ao morfolóxico, sintáctico e léxico-semántico" (González González, 2008: 364).

Infelizmente, non hai aínda na Galiza un traballo ben fundamentado que examine as diferenzas entre o discurso das persoas neofalantes e españolfalantes en todos os niveis da lingua. Porén, xa se están a dar os primeiros pasos nesa dirección, de que son proba os contributos que teñen por título "The effects of language dominance in the perception and production of the Galician mid vowel contrasts" (Amengual \& Chamorro, 2015), The role of social factors in bilingual speech processing: the case of Galician New Speakers (Tomé Lourido, 2018) e "Os neofalantes galegos no contexto europeo: A produción e a percepción da fala" (Tomé Lourido \& Evans, 2018), todos eles centrados no estudo dos planos fonético e fonolóxico da lingua e, máis particularmente, nas distintas variábeis que afectan as persoas neofalantes no que di respecto á produción e á percepción adecuada dos sons das variedades tradicionais. 


\section{Consideracións finais}

Após o percurso seguido nas páxinas precedentes, non resta ningunha dúbida de o destino do galego estar ligado, en grande parte, á emerxencia de neofalantes no panorama sociolingüístico galego. Así, ao longo das diversas seccións que conforman este artigo, abordamos tan pormenorizadamente canto posíbel algunhas cuestións centrais que abranxen desde a análise do fenómeno do neofalantismo na Galiza, con énfase na definición, na tipoloxía, no perfil ideolóxico e nos modelos de lingua deste novo usuariado, até ao estabelecemento dun marco teórico a respecto dos conceptos de "neofalante" e de "neofalantismo", tendo en conta a evolución das diferentes correntes europeas, peninsulares e galegas no dominio dos estudos sobre as linguas minorizadas. Neste sentido, a nosa exposición revela a complexidade e a multiplicidade de dimensións deste fenómeno, ao paso que verifica o papel chave deste colectivo no porvir do idioma galego. Igualmente, conforme xa demostrado, a grande cantidade de contributos neste dominio tanto a nivel internacional canto nacional evidencia que este é un tema de actualidade que está a despertar un grande interese no ámbito da pesquisa sociolingüística, nomeadamente sobre as linguas minorizadas e/ou minoritarias.

No caso concreto do galego, a pesar de non existir unha monografía que forneza unha panorámica pormenorizada e abranxente sobre o fenómeno do neofalantismo, debe resaltarse a proliferación na última década de traballos académicos sobre esta cuestión, consoante a importancia que este fenómeno social posúe para a revitalización e a sobrevivencia da lingua galega. Por esta razón, na nosa opinión, resulta prioritario proseguirmos o desenvolvemento desta liña de investigación, dando particular atención ao estudo dos trazos fonéticos, morfolóxicos, sintácticos etc. Que caracterizan os distintos modelos de lingua das persoas neofalantes, ben como á evolución lingüística idiolectal dos suxeitos que fan parte deste colectivo. Con certeza, só coñecéndomos con precisión a realidade sociolingüística galega poderemos formular e adoptar medidas adecuadas e eficaces que contribúan tanto para a atracción de novos e novas falantes como para a manutención dos e das actuais.

\section{Referencias bibliográficas}

Amengual, Mark, \& Chamorro, Pilar (2015). "The effects of language dominance in the perception and production of the Galician mid vowel contrasts", Phonetica, 72(4), 207-236. DOI: http://dx.doi.org/10.1159/000439406. 
Atkinson, David (2018). "New Speakers and Linguistic Practices: Contexts, Definitions, and Issues". En Smith-Christmas, Cassie, Murchadha, Noel P. Ó, Hornsby, Michael, Smith-Christmas, Cassie, \& Moriarty, Máiréad (eds.), New Speakers of Minority Languages: Linguistic Ideologies and Practices, 271-282. London: Palgrave Macmillan. DOI: https://doi.org/10.1057/978-1-137-57558-6_14.

Chomsky, Noam (1971). Aspectos de la teoría de la sintaxis. Trad. De Carlos P. Otero. Madrid: Aguilar. [Título orixinal: Aspects of the Theory of Syntax, 1965].

Coluzzi, Paolo (2018). “The new speakers of Lombard”, Multilingua, 1-25. DOI: https:// doi.org/10.1515/multi-2018-0017.

Costa, James (2015). "New Speakers, New Language: On Being a Legitimate Speaker of a Minority Language in Provence", International Journal of the Sociology of Language, 231(1), 127-145. DOI: https://doi.org/10.1515/ijsl-2014-0035.

Crystal, David (2003). A morte das linguas. Trad. De Mariña Castro Eiroa. Vigo: Galaxia. [Título orixinal: Language Death, 2000].

Dans, Manuel B. (2017). Historias de neofalantes. A aventura de vivermos en galego. Betanzos: Asociación Cultural Eira Vella.

Davies, Alan (2003). The Native Speaker: Myth and Reality. Clevedon: Multilingual Matters.

Dorian, Nancy C. (1980). "Language Shift in Community and Individual: The Phenomenon of the Laggard Semi-Speaker", International Journal of the Sociology of Language, 25, 85-94. DOI: https://doi.org/10.1515/ijsl.1980.25.85.

Dorian, Nancy C. (1981). Language Death. The Life Cycle of a Scottish Gaelic Dialect. Philadelphia: University of Pennsylvania Press.

Dubert, Francisco (2002). “Os sociolectos galegos”, Cadernos de Lingua, 24, 5-27.

Ferguson, Gibson (2006). Language Planning and Education. Edinburgh: Edinburgh University Press.

Fishman, Joshua A. (1991). Reversing language shift: Theoretical and empirical foundations of assistence to threatened languages. Clevedon \& Philadelphia: Multilingual Matters.

Fishman, Joshua A. (1997). O mantemento e o cambio de lingua coma campo de investigación. Trad. De Manuel Fernández Ferreiro. Valencia: Centro de Estudios sobre Comunicación Interlingüística e Intercultural. [Título orixinal: Language Maintenance and Language Shift as a field of inquiry. A definition of the field and suggestions for its further development, 1964].

Fishman, Joshua A. (2001). "Why is it so hard to save a threatened language?". En Fishman, Joshua A. (ed.), Can threatened languages be saved? Reversing language shift, revisited: A 21st century perspective, 1-22. Clevedon: Multilingual Matters. 
Freixeiro Mato, Xosé Ramón (2009). “Lingua galega e preconcepto”, Revista Galega de Filoloxía, 10, 115-144.

Freixeiro Mato, Xosé Ramón (2010). "Perigos, incertezas e perspectivas de futuro para a lingua galega”. En Sanmartín Rei, Goretti (coord.), Lingua e futuro, 13-54. Ames: Laiovento.

Frías Conde, Xavier (2006). “A normalización lingüística na Romania: a normalización da lingua e normalización dos falantes (o caso dos neofalantes)", Ianua. Revista Philologica Romanica, 6, 49-68.

González González, Manuel (dir.) (2003). O galego segundo a mocidade. Unha achega ás actitudes e discursos sociais baseada en técnicas experimentais e cualitativas. A Coruña: Real Academia Galega.

González González, Manuel (2008). “O novo galego urbano”. En Brea, Mercedes, Fernández Rei, Francisco, \& Regueira, Xosé Luís (eds.), Cada palabra pesaba, cada palabra media. Homenaxe a Antón Santamarina, 363-374. Santiago de Compostela: Universidade de Santiago de Compostela.

Hornsby, Michael (2015). “The 'new' and 'traditional' speaker dichotomy: bridging the gap", International Journal of the Sociology of Language, 231(1), 107-125. DOI: https://doi. org/10.1515/ijsl-2014-0034.

Hornsby, Michael (2016). "Finding an ideological niche for new speakers in a minoritised language community”, Language, Culture and Curriculum, 30(1), 1-14. DOI: https:// doi.org/10.1080/07908318.2016.1230622.

Iglesias Álvarez, Ana (2002). Falar galego "no veo por qué": Aproximación cualitativa á situación sociolingüística de Galicia. Vigo: Xerais.

IGE, 2011= Instituto Galego de Estatística (2011). Censo de poboación e vivendas. Galego. Ano 2011. Santiago de Compostela: Xunta de Galicia.

Jaffe, Alexandra (2015). "Defining the new speaker: theoretical perspectives and learner trajectories", International Journal of the Sociology of Language, 231, 21-44. DOI: https://doi.org/10.1515/ijsl-2014-0030.

Kabatek, Johannes (2000). Os falantes como lingüistas. Tradición, innovación e interferencias no galego actual. Trad. do autor revisada por María Xesús Bello Rivas. Vigo: Xerais. [Título orixinal: Die Sprecher als Linguisten: Interferenz- und Sprachwandelphänomene dargestellt am Galicischen der Gegenwart, 1996].

Kováčová-Moman, Vlasta (2007). A mudança da língua usual nos novos locutores de galego - neofalantes. Santiago de Compostela: Gze-ditora. https://agal-gz.org/faq/ lib/exe/fetc h.php?media=gze-ditora:a_mudanca_de_lingua.pdf (Consultado en 14.03.2019).

Lantto, Hanna (2018). "New Basques and Code-Switching: Purist Tendencies, Social Pressures”. En Smith-Christmas, Cassie, Murchadha, Noel P. Ó, Hornsby, Michael, 
Smith-Christmas, Cassie, \& Moriarty, Máiréad (eds.), New Speakers of Minority Languages: Linguistic Ideologies and Practices, 165-188. London: Palgrave Macmillan. DOI: https://doi.org/10.1057/978-1-137-57558-6_9.

Lorenzo Suárez, Anxo M. (2005). "Planificación lingüística de baixa intensidade: o caso galego", Cadernos de Lingua, 27, 37-59.

Marten, Heiko F., van Mensel, Luk, \& Gorter, Durk (2012). "Studying Minority Languages in the Linguistic Landscape". En Gorter, Durk, Marten, Heiko F., \& Van Mensel, Luk (eds.), Minority languages in the linguistic landscape, 1-15. Basingstoke: Palgrave-Macmillan.

May, Stephen (2008). Language and minority rights: ethnicity, nationalism and the politics of language. New York: Routledge.

McLeod, Wilson, \& O’Rourke, Bernadette (2015). “«New speakers» of Gaelic: perceptions of linguistic authenticity and appropriateness", Applied Linguistics Review, 6(2), 152-172. DOI: https://doi.org/10.1515/applirev-2015-0008.

McLeod, Wilson, O'Rourke, Bernadette, \& Dunmore, Stuart (2014). New speakers of Gaelic in Edinburgh and Glasgow. Edinburgh: Soillse. http://www.soillse.ac.uk/ wp-content/uploads/New-Speakers\%E2\%80\%99-of-Gaelic-in-Edinburgh-andGlasgow.pdf (Consultado en 10.03.2019).

Monteagudo, Henrique (2005). "Do uso á norma, da norma ao uso (Variación sociolingüística e estandarización no idioma galego)". En Álvarez, Rosario, \& Monteagudo, Henrique (eds.), Norma lingüistica e variación, 377-436. Santiago de Compostela: Consello da Cultura Galega \& Instituto da Lingua Galega.

Monteagudo, Henrique (2017). "Lingua e Sociedade en Galicia", LaborHistórico, 3(1), 14-48. DOI: http://dx.doi.org/10.24206/lh.v3i1.17105.

Monteagudo, Henrique, Loredo, Xaquín, \& Vázquez, Martín (2016). Lingua e Sociedade. A evolución sociolingüística 1992-2013. A Coruña: Real Academia Galega.

Moscovici, Serge, \& Mugny, Gabriel (1983). "Minority influence”. En Paulus, Paul B. (ed.), Basic Group Processes, 41-64. New York: Springer-Verlag.

Mosquera Castro, Estefanía (2018). "Neofalantes e travestismo lingüístico: un experimento sociolóxico e didáctico sobre ideoloxías, obstáculos e persistencia". En Díaz, Marta, Vaamonde, Gael, Varela, Ana, Cabeza, Ma Carmen, García-Miguel, José M., \& Ramallo, Fernando (eds.), Actas do XIII Congreso Internacional de Lingüística Xeral, 655-661. Vigo: Universidade de Vigo.

MSG, 2007= González González, Manuel (dir.) (2007). Mapa sociolingüístico de Galicia 2004. Vol. I: Lingua inicial e competencia lingüistica en Galicia. A Coruña: Real Academia Galega.

MSG, 2008= González González, Manuel (dir.) (2008). Mapa sociolingüístico de Galicia 2004. Vol. II: Usos lingüisticos en Galicia. A Coruña: Real Academia Galega. 
MSG, 2011= González González, Manuel (dir.) (2011). Mapa sociolingüístico de Galicia 2004. Vol. 3: Actitudes lingüísticas en Galicia. A Coruña: Real Academia Galega.

Murchadha, Noel P. Ó, Hornsby, Michael, Smith-Christmas, Cassie, \& Moriarty, Máiréad (2018). "New Speakers, Familiar Concepts?”. En Smith-Christmas, Cassie, Murchadha, Noel P. Ó, Hornsby, Michael, Smith-Christmas, Cassie, \& Moriarty, Máiréad (eds.), New Speakers of Minority Languages: Linguistic Ideologies and Practices, 1-22. London: Palgrave Macmillan. DOI: https://doi.org/10.1057/978-1137-57558-6_1.

Ninyoles, Rafael L. (2005). Idioma e poder social. Trad. De María Pilar García Negro e Antonio Molexón Domínguez. Ames: Laiovento. [Título orixinal: Idioma y poder social, 1972].

Observatorio da Cultura Galega (2011). A(s) lingua(s) a debate: Inquérito sobre opinións, actitudes e expectativas da sociedade galega. Santiago de Compostela: Consello da Cultura Galega.

Observatorio da Cultura Galega (2017). Prácticas e actitudes lingüísticas da mocidade en Galicia. Santiago de Compostela: Consello da Cultura Galega.

O'Rourke, Bernadette (2011). Galician and Irish in the European Context: Attitudes towards Weak and Strong Minority Languages. Hampshire: Palgrave Macmillan. DOI: http://dx.doi.org/10.1057/9780230294820.

O'Rourke, Bernadette (2014). "The Galician Language in the Twenty-First Century". En Miguélez-Carballeira, Helena (ed.), A Companion to Galician Culture, 73-92. Suffolk: Tamesis.

O'Rourke, Bernadette (2018). "Just use it! Linguistic conversion and identities of resistance amongst Galician new speakers", Journal of Multilingual and Multicultural Development, 39(5), 407-418. DOI: https://doi.org/10.1080/0143463 2.2018.1429455.

O’Rourke, Bernadette, \& Pujolar, Joan (2013). "From native speakers to "new speakers"-Problematizing nativeness in language revitalization contexts", Histoire Épistémologie Langage, 35(2), 47-67.

O’Rourke, Bernadette, \& Ramallo, Fernando (2011). "Los nuevos hablantes de lenguas minoritarias: una comparación entre Irlanda y Galicia", Actas del IX Congreso Internacional de Lingüistica General, 1684-1700. Valladolid: Universidad de Valladolid. https://www.academia.edu/1168315/Los_nuevos_hablantes_de_lenguas_minoritarias_una_comparaci\%C3\%B3n_entre_Irlanda_y_Galicia (Consultado en 10.03 . 2019).

O’Rourke, Bernadette, \& Ramallo, Fernando (2013a). "«A miña variedade é defectuosa»: a lexitimación social das neofalas”, Estudos de Lingüística Galega, 5, 89-103. 
O'Rourke, Bernadette, \& Ramallo, Fernando (2013b). "Competing ideologies of linguistic authority amongst newspeakers in contemporary Galicia", Language in Society, 42, 287-305. DOI: https://doi.org/10.1017/S0047404513000419.

O'Rourke, Bernadette, \& Ramallo, Fernando (2015). "Neofalantes as an active minority: Understanding language practices and motivations for change amongst new speakers of Galician", International Journal for the Sociology of Language, 231, 147-165. DOI: https://doi.org/10.1515/ijsl-2014-0036.

O'Rourke, Bernadette, \& Ramallo, Fernando (2018). "Identities and New Speakers of Minority Languages: A Focus on Galician". En Smith-Christmas, Cassie, Murchadha, Noel P. Ó, Hornsby, Michael, Smith-Christmas, Cassie, \& Moriarty, Máiréad (eds.), New Speakers of Minority Languages: Linguistic Ideologies and Practices, 91-109. London: Palgrave Macmillan. DOI: https://doi.org/10.1057/978-1-137-57558-6_5.

O’Rourke, Bernadette, Pujolar, Joan, \& Ramallo, Fernando (2015). "New speakers of minority languages: The challenging opportunity - Foreword", International Journal of the Sociology of Language, 231, 1-20. DOI: https://doi.org/10.1515/ijsl-2014-0029.

O’Rourke, Bernadette, \& Walsh, John (2015). "New speakers of Irish: Shifting boundaries across time and space", International Journal of the Sociology of Language, 231, 6383. DOI: https://doi.org/10.1515/ijsl-2014-0032.

Ortega, Ane, Amorrortu, Estibaliz, Goirigolzarri, Jone, Urla, Jacqueline, \& Uranga, Belén (2014). "Nuevos hablantes de euskera: identidad y legitimidad". En Puigdevall, Maite (coord.), Los nuevos hablantes de lenguas minoritarias: pertinencias y legitimidades [dossier en liña], Digithum, 16, 86-97. https://www.raco.cat/index.php/Digit/article/ viewFile/304440/394158 (Consultado en 22.03.2019).

Padín, Paulo (2017). Neofalantes na Era Digital. Barcelona: Universitat Oberta de Catalunya. http://hdl.handle.net/10609/66845 (Consultado en 15.02.2019).

Paikeday, Thomas M. (1985). The Native speaker is dead!. Toronto \& New York: Paikeday.

Piller, Ingrid (2001). "Who, if anyone, is a native speaker?", Anglistik. Mitteilungen des Verbandes Deutscher Anglisten, 12(2), 109-121.

Piller, Ingrid (2002). "Passing for a native speaker: Identity and success in second language learning", Journal of Sociolinguistics, 6(2), 179-206.

Puigdevall, Maite, Walsh, John, Amorrortu, Estibaliz, \& Ortega, Ane (2018). “«I'll be one of them»: linguistic mudes and new speakers in three minority language contexts", Journal of Multilingual and Multicultural Development, 39(5), 445-457. DOI: https://doi.org/10.1080/01434632.2018.1429453.

Pujolar, Joan, González, Isaac, \& Martínez, Roger (2010). "Les mudes lingüístiques dels joves catalans [versión en español do autor]", Llengua i ús, 48, 65-75. http://www6. gencat.net/llengcat/liu/48_42.pdf(Consultado en 19.03.2019). 
Pujolar, Joan, \& Puigdevall, Maite (2015). "Linguistic mudes: how to become a new speaker in Catalonia", International Journal of the Sociology of Language, 231, 167-187. DOI: https://doi.org/10.1515/ijsl-2014-0037.

Ramallo, Fernando (2010). "Cara a unha tipoloxía sociolingüística dos falantes de galego". En Silva, Bieito, Rodríguez, Xesús, \& Vaquero, Isabel (eds.), Educación e linguas en Galicia, 15-37. Santiago de Compostela: Universidade de Santiago de Compostela.

Ramallo, Fernando (2012). "El gallego en la familia: entre la producción y la reproducción”, Caplletra, 53, 167-191.

Ramallo, Fernando (2013). "Neofalantismo". En Gugenberger, Eva, Monteagudo, Henrique, \& Rei-Doval, Gabriel (eds.), Contacto de linguas, hibrididade, cambio: contextos, procesos e consecuencias, 245-258. Santiago de Compostela: Consello da Cultura Galega.

Ramallo, Fernando (2018). "O neofalantismo e o suxeito neofalante”. En Díaz, Marta, Vaamonde, Gael, Varela, Ana, Cabeza, Ma Carmen, García-Miguel, José M., \& Ramallo, Fernando (eds.), Actas do XIII Congreso Internacional de Lingüística Xeral, 737-743. Vigo: Universidade de Vigo.

Ramallo, Fernando, \& O'Rourke, Bernadette (2014). "Perfiles de neohablantes de gallego", Digithum, 16, 98-105.

Regueira, Xosé Luís (1999). "Estándar oral e variación social da lingua galega". En Álvarez, Rosario, \& Vilavedra, Dolores (eds.), Cinguidos por unha arela común: homenaxe ó profesor Xesús Alonso Montero, 855-875. Santiago de Compostela: Universidade de Santiago de Compostela.

Selleck, Charlotte (2018). "«We're Not Fully Welsh»: Hierarchies of Belonging and 'New' Speakers of Welsh”. En Smith-Christmas, Cassie, Murchadha, Noel P. Ó, Hornsby, Michael, Smith-Christmas, Cassie, \& Moriarty, Máiréad (eds.), New Speakers of Minority Languages: Linguistic Ideologies and Practices, 45-66. London: Palgrave Macmillan. DOI: https://doi.org/10.1057/978-1-137-57558-6_3.

Spolsky, Bernard (ed.) (2012). The Cambridge Handbook of Language Policy. Cambridge: Cambridge University Press.

Tomé Lourido, Gisela (2018). The role of social factors in bilingual speech processing: the case of Galician New Speakers (tese de doutoramento inédita). London: University College London. http://giselatome.com/documents/Tome-Lourido_2018_digital.pdf (Consultado en 23.03.2019).

Tomé Lourido, Gisela, \& Evans, Bronwen G. (2018). “Os neofalantes galegos no contexto europeo: A produción e a percepción da fala”. En Regueira, Xosé Luís, \& Fernández Rei, Elisa (eds.), Cambio lingüístico no galego actual, 99-128. Santiago de Compostela: Instituto da Lingua Galega \& Consello da Cultura. 
Urla, Jacqueline (2012). Reclaiming Basque: Language, Nation, and Cultural Activism. Las Vegas: University of Nevada Press.

Weinreich, Uriel (1979). Languages in contact. Findings and problems (9. ${ }^{a}$ edición). The Hague: Mouton. 